\title{
EFFICIENCY OF HALOTHERAPY IN IMPROVING HUMAN PERFORMANCE IN GYMNASIUM STUDENTS)
}

DOI: https://doi.org/10.18509/AGB217-40167a

UDC: $615.834-057.875$

\author{
Mihaela-Orlanda Antonovici (Munteanu) ${ }^{1}$, Ion Sandu ${ }^{2,3}$, \\ Ioan Gabriel Sandu ${ }^{4,5}$, Cristina Carmen Stingu (Palici) ${ }^{6}$, \\ Simona Dimitriu (Ursache) ${ }^{1}$
}

\author{
${ }^{\prime}$ Alexandru Ioan Cuza University, Faculty of Geography and Geologie, Geoscience Doctoral School, Environmental \\ Science Field, Iasi, România \\ ${ }^{2}$ Alexandru Ioan Cuza University, ARHEOINVEST Interdisciplinary Platform, Iasi, Romania \\ ${ }^{3}$ Romanian Inventors Forum, Iaşi, Romania \\ ${ }^{4}$ Alexandru Ioan Cuza University of Iasi, Interdisciplinary Research Department - Field Science, Iaşi, Romania \\ ${ }^{5}$ Gheorghe Asachi Technical University of Iasi, Faculty of Material Sciences and Engineering Iaşi, Romania \\ ${ }^{6}$ Vasile Alecsandri University of Bacau, Department of Environmental Engineering and \\ Mechanical Engineering, Bacau, Romania
}

corresponding author:

\begin{abstract}
The paper presents on the basis of studies conducted in recent years in our team on the generation, chemical, physical and structural characterization and dynamics of saline aerosols, their role in increasing the anatomical structural performance for students. Halotherapy is performed by inhaling saline aerosols through the airways, as well as by absorbing them on the skin. The salt nanoparticles have a considerable negative charge $\left(6-10 \mathrm{nK} / \mathrm{m}^{3}\right)$, and the surface of the airway has a slight positive charge, with a wide range of dimensions, from the Aitken type (between the single ion, as such or solvate, and nanostructural aggregates smaller than $50 \mu$ to the sedimentable aggregate (with a diameter greater than $500 \mu$ to $1000 \mu$ ) [1].Regarding these nanoparticles, a series of artificial halochambers were developed, which were experimented in teaching activities with students, in Physical Education classes and for other study disciplines. Thus, a series of diaphragm generators containing porous $\mathrm{NaCl}$ granules were used, obtained by recrystallization from supersaturated solutions and which were arranged in the classrooms (two in number), as well as in the gym, which operated. as halochambers. Students were monitored twice a week for the evolution of morphostructural and biometric characteristics. For each work program, the level of saline aerosols / solions was correlated with the average data of the biometric characteristics of the students, separated by sex. For Aitken particles, the lifespan varies between 12 and 72 hours. Thus, it was proved by the obtained results that these nanoparticles have a beneficial influence on the development of high school students, females having higher receptivity to the effect of improving human performance.
\end{abstract}

Keywords anhydrous saline aerosols, solions, Aitken particles, halochamber, halotherapy.

\section{INTRODUCTION}

The paper aims to study the impact of saline aerosols on morpho-structural and functional characteristics of students, as well as on the evolution of their health, focusing on the harmonious development of human subjects studied, students of grades VI and VII, with ages 12-15. Therapy with natural or artificial saline aerosols is considered a procedure for the prevention and treatment of respiratory diseases, as it contributes to increasing resistance to weathering, aggression of gases and dusts in the air, thus reducing long-term drug treatment and improving school activity while reducing the number of missed classes through medical exemption. The salt particles contribute to the increase of the organism's resistance against respiratory infections and have desensitizing effects to allergens, having a considerable negative charge $(6-10 \mathrm{nK} / \mathrm{m} 3)$, and the surface of the airways has a slight positive electric charge, therefore, the salt have the ability to enter the respiratory system and "bind" to the airway epithelium.Working with high school 
students, such on-site research would benefit both the health of the students and the school in improving school performance and maintaining a healthy climate. The movement in the halochamber increases the resistance to stress, improves the power of concentration, offers emotional stability and a general state of comfort. Saline aerosols also have positive effects on the skin system. According to literature, they normalize skin microbiocenosis, increase skin elasticity and have a bacteriostatic, anti-edematous and anti-inflammatory effect. The therapeutic potential of natural or artificial saline aerosols is in the attention of researchers around the world to obtain new scientific, argumentative data

\section{THE EXPERIMENTAL PART}

\section{Methods and techniques used in determining the characteristics of saline aerosols}

Both methods for determining the climatic parameters of an enclosure and a series of specific methods were used to measure and monitor the composition of the atmosphere in the halocamera, such as: SIBATA GT 321 particle counter and Dust Trok, a ionometer type Air Ion Counter and climatic factors in the classrooms involved were monitored as follows:

temperature $\left({ }^{\circ} \mathrm{C}\right)$, air humidity $\left(\begin{array}{ll}\% & \mathrm{RH}\end{array}\right)$, atmospheric pressure (mmHg) and lighting (lx), using specific laboratory devices.

\section{Work Methodology}

The study used semi-dry aeration generating devices, consisting of a fan and a diaphragm containing porous granules extruded from recrystallized rock salt from supersaturated solutions. \% RH and $20 \ldots 22^{\circ} \mathrm{C}$ ). In the classrooms where the study was conducted, four generators were placed at the level of the windows, with a volume of $126 \mathrm{~m} 3$ of air $(7 \times 6 \times 3)$ and six in the gym of $320 \mathrm{~m} 3(10 \times 8 \times 4)$. To achieve an optimal level in

\section{Selecting the groups of students for the trials}

The trials were performed on students in grades VI and VII, from which there were selected for each age category, noted by year of birth (2006 and 2007), two groups of students (girls and boys): the reference group for applications outdoors or gym, composed of the group of girls marked F0i200X (X $=6$ and 7), consisting of students $i$, with the year of birth 200X and the group of boys marked B0i200X, composed of the student $i$, with the year of birth 200X and respectively the batch group consisting of the group of girls marked Fhi200X with students i, with the year of birth 200X and the group of boys marked Bhi200X with the student $i$, with the year of birth $200 \mathrm{X}$, where $\mathrm{i}=1,2,3 \ldots$, represents the to support these holistic therapies [1]. Related to these nanoparticles, a series of patented artificial halochambers were developed, which were experimented in teaching activities with students. With their help, it has been shown that active solions at a certain level of concentration have a beneficial influence on the development of young people, the female sex having a higher receptivity regarding the effect of improving human performance [2],[3]. In this sense, the influence of the active time of standing in the halochamber is studied, which is ten times longer than in other studies of the team [4],[5]..

solutions, the generators were turned on about 60 minutes before the start of class. After 50 minutes of operation, the average level of solion was determined, and then determined again at the end of the hours. For the Physical Education classes followed a progressive program of exercises, trainings and games for a period of 50 minutes, twice a week, distributed at intervals approximately close in time. The fans allow the circulation of 28 $32 \mathrm{~m} 3 / \mathrm{h}$, so $112-128 \mathrm{~m} 3 / \mathrm{h}$, respectively, 168$192 \mathrm{~m} 3 / \mathrm{h}$. Saline aerosol generators, by erosion, take up nanoparticles of salts from the labile crystallites of the efflorescences on the surface of the granules and disperse them into the halochamber atmosphere, where under the influence of air humidity they are structurally reformulated as oligomers of salt and pentahydrol nanocrystallites. spherical glomeruli with negative aeroion behavior. The glomeruli have a superficial monomolecular layer of water dipoles with a negative charge on the outside.

number of the student in the group, each group with 7 to 25 students.

In order to select students for the two experimental groups (halochamber and outdoor) a series of data were used according to a standard form that includes information on family living conditions, heredocolateral history (hemophilia, diabetes, hypertension, parasitosis). , heart disease, cancer, rheumatic diseases, TB), personal physiological, pathological history (eruptive diseases, whooping cough, hepatitis, gastritis, cardiovascular, immunological, metabolic and endocrine disorders). Following the examination of the subjects and the analysis of the completed forms, 
the following were established: living conditions, type of family, global attitude of the body and others .Students were closely monitored during the school year so that twice a week (Tuesday and Friday), at the beginning and end of the week, in terms of morphostructural and biometric characteristics. For each work program, the level of saline aerosols / solutions was correlated with the average data of the biometric characteristics of the students, separated by sex [6].

Table 1. The climatic characteristics of the two systems used in the experiment (open air and halochamber).

\begin{tabular}{|c|c|c|c|c|c|c|}
\hline The system & The parameter & Oct 2017 & Oct 2018 & Feb.2019 & Oct.2020 & Feb.2021 \\
\hline \multirow{4}{*}{$\begin{array}{c}\text { Open air or } \\
\text { gym } \\
\text { (witness) }\end{array}$} & $\mathrm{T}^{\circ} \mathrm{C}$ & 20 & 20 & 20 & 21 & 20 \\
\hline & $\mathrm{P}, \mathrm{atm}$ & 750 & 740 & 740 & 750 & 750 \\
\hline & UR, \% & 70 & 60 & 65 & 60 & 60 \\
\hline & $\mathrm{I}, \mathrm{lx}$ & 120 & 116 & 112 & 118 & 120 \\
\hline \multirow{5}{*}{$\begin{array}{c}\text { Halochamber } \\
\text { I and II }\end{array}$} & $\mathrm{C}, \mathrm{mg} / \mathrm{m}^{3}$, saline aerosols & 0,649 & 0,667 & 0,682 & 0,669 & 0,705 \\
\hline & $\mathrm{T}^{\circ} \mathrm{C}$ & 20 & 20 & 20 & 21 & 20 \\
\hline & $\mathrm{P}, \mathrm{atm}$ & 750 & 740 & 740 & 750 & 750 \\
\hline & UR, \% & 65 & 65 & 65 & 60 & 65 \\
\hline & $\mathrm{I}, \mathrm{lx}$ & 85 & 80 & 80 & 82 & 85 \\
\hline $\begin{array}{c}\text { Classroom } \\
\text { I and II } \\
\text { witness }\end{array}$ & $\begin{array}{l}\mathrm{C}, \mathrm{mg} / \mathrm{m}^{3}, \text { saline aerosols } \\
\mathrm{T} \circ \mathrm{C}, \\
\mathrm{P}, \mathrm{atm} \\
\mathrm{UR}, \% \\
\mathrm{I}, \mathrm{lx}\end{array}$ & $\begin{array}{l}0 \\
21 \\
750 \\
75 \\
110\end{array}$ & $\begin{array}{l}0 \\
22 \\
740 \\
70 \\
105\end{array}$ & $\begin{array}{l}0 \\
22 \\
760 \\
75 \\
110\end{array}$ & $\begin{array}{l}0 \\
22 \\
760 \\
75 \\
120\end{array}$ & $\begin{array}{l}0 \\
21 \\
750 \\
70 \\
110\end{array}$ \\
\hline
\end{tabular}

\section{Determining the Biometric Characteristics}

During the morpho-structural and functional biometric examination, in order to determine the level of physical development of the subjects, a series of measurements were performed, namely:

- the weight, which was performed with the help of the electronic scale and was expressed in kilograms;

- stature (height), which was determined with the staturometer, being expressed in centimeters;

- the thoracic perimeter, respectively the thickness of the thorax, was measured with a metric band $(100 \mathrm{~cm})$, registering two dimensions, with the thoracic perimeter at respiratory rest (moment between inspiration and expiration) and respectively the thoracic perimeter in maximum inspiration, this study was presented in a previous communication [7]. In the present paper only the following characteristics are studied:

- lung capacity, determined by means of the portable spirometer Peak Flow Meter PFM20, Peak A-I-R, Omron, the maximum volume of exhaled air expressed in $\mathrm{L} / \mathrm{min}$, and

- pulse or heart rate, determined by the device digital sphygmomanometer HZ-8501.

\section{Processing trial data}

Since we worked with a heterogeneous group of students with many characteristics dependent on exogenous factors (environmental), but also on endogenous ones (genetic dowry), in order to facilitate the interpretation of experimental results we resorted to the graphical representation of the growth percentage in time. In order to do this, the biometric data were determined periodically, at 12 ,
24 , and 40 months, respectively, to establish the evolution of the maximum expired air volume for the students studied. Based on the recorded data, a primary table was prepared. Then the average of the values for the same period evaluated for each group of students was calculated, respectively the group of girls, denoted F0m200X and the group of boys, denoted B0m200X, where $\mathrm{m}$ represents the arithmetic mean, and $X$ - the values 6, 7, corresponding to the year of birth. After this, the percentage $(\%)$ was calculated by how much the characteristic $\mathrm{C}$ evolved, compared to the start time of the experiment $\left(\mathrm{C}_{0}\right)$, in relation to the subsequent readings $(\mathrm{Cj})$, the determination period being denoted by $j$, which represents the month of the year of readings, using the relationship:

$$
\begin{gathered}
\mathrm{C}(\%) \mathrm{F}_{0 \mathrm{~m}} 200 \mathrm{X} \text { or } \mathrm{C}(\%) \mathrm{B}_{0 \mathrm{~m}} 200 \mathrm{X}=100 \times(\mathrm{Cj}- \\
\mathrm{C} 0) / \mathrm{C}_{0}, \\
\text { respectively, } \\
\mathrm{C}(\%) \mathrm{F}_{\mathrm{hm}} 200 \mathrm{X} \text { or } \mathrm{C}(\%) \mathrm{B}_{\mathrm{hm}} 200 \mathrm{X}=100 \times(\mathrm{Cj}- \\
\left.\mathrm{C}_{0}\right) / \mathrm{C}_{0} ;
\end{gathered}
$$

Finally, the graphs $\mathrm{C}(\%)=\mathrm{f}(\mathrm{t})$ are drawn, the time being in months, for the average values of girls and boys, in the two different working conditions, taken separately (outdoors, noted in the lower right index " 0 " and halochamber, denoted in the lower right index "h"). Each biometric characteristic studied was represented in the same coordinate system, having in ordinate $\mathrm{C}(\%)$ and in abscissa time in months. Based on these graphs, the evolution of each group of students was assessed and the influence of saline aerosols and reformulations in situ on the characteristics studied was established. 


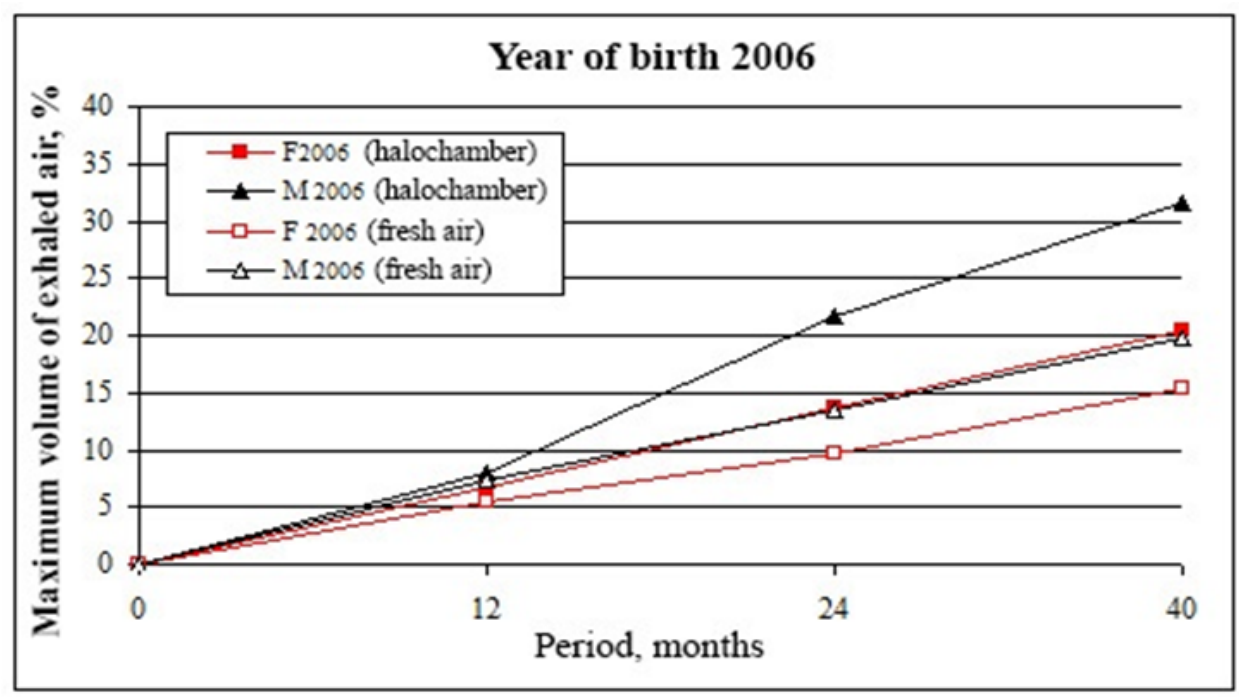

Figure 1. The evolution of the maximum expired air volume for the students born in 2006 taken in the study.

The primary data were recording in a tabular system, followed by their processing and graphical representation of the evolution over time of morphostructural characteristics (weight, height, thoracic perimeter), which was studied and presented in a previous article for each group of students on the two age levels $(2006,2007)$ and gender [7].

Regarding the evolution of the maximum volume of exhaled air, in the case of students born in 2006 there was a higher increase in the case of boys (Fig. 1), the difference between the percentage increases recorded by the group in the halochamber and the control group being $11.91 \%$ for boys and only $5.21 \%$ for girls. It should be noted that in the first 12 months the percentage increases for girls and boys are very close, and only after this interval the group of boys who worked in the halochamber registered a more accentuated increase.

For the groups of students born in 2007, the evolution of the maximum volume of exhaled air (Fig. 2) shows a clear difference between the percentage increase of the volume of exhaled air in girls compared to boys, the value of this percentage reaching up to $24.48 \%$ in the case of girls, compared to only $18.30 \%$ among boys.

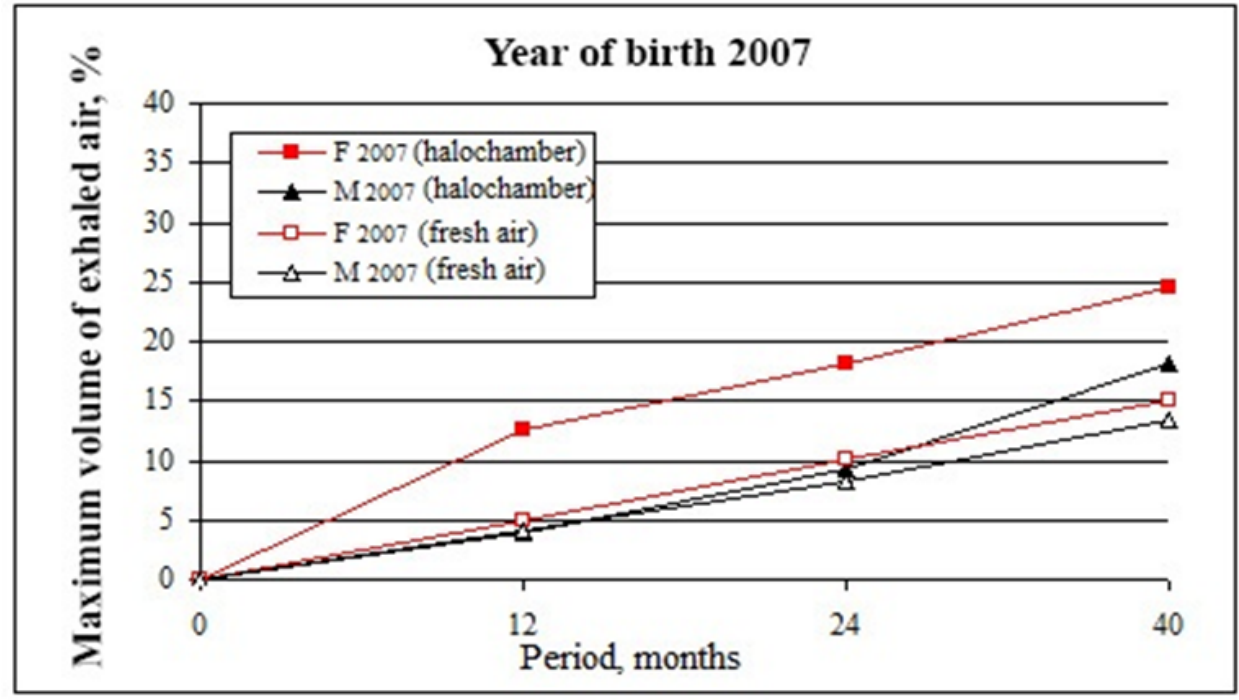

Figure 2 The evolution of the maximum expired air volume for the students born in 2007 taken in the study

The groups that operated outdoors only slightly exceeded the threshold of $15.00 \%$ (15.09\% boys, $13.33 \%$ girls), the percentage of growth registering close values throughout the monitoring. In the first 24 months, the percentage values recorded in the evolution of the group of boys who carried out activities in the halochamber were close to those of the control groups and then distanced quickly, while the percentage evolution of the maximum volume of expired air only currently displaying higher growth rate. Regarding the evolution of heart rate or pulse, in the case of the group born in 2006 
(Fig.3), there is a decrease in the number of beats / minute recorded after exertion, the decrease being more pronounced in the case of boys. At the beginning of the study period, the difference between the average pulse recorded before and after exertion in boys who worked in the halochamber was 39 beats / min, and at the end of the period it reached 25 beats / min. A more pronounced reduction in the difference between the values recorded at rest and those after exercise is observed after the first 24 months. The common peak recorded at measurements taken after 24 months can be attributed to health problems.

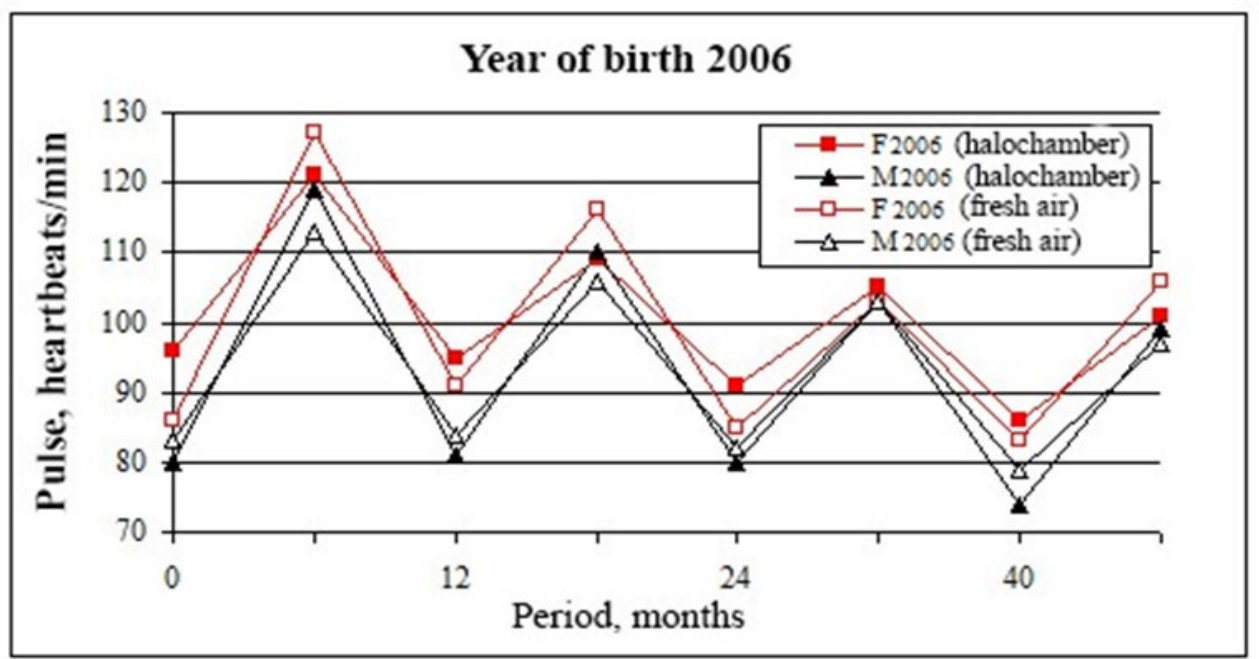

Figure 3. Evolution of the pulse for students born in 2006 studied

For the groups born in 2007 the pulse registered in the first 12 months (Fig. 4), indicates approximately the same values after the effort, same the girl group as for the boy group. Then, after the first 12 months, there is a decrease in the number of beats / minute, after the effort the decrease is more pronounced in girls $(\mathrm{Fhm} 2007=123-103$ beats $/ \mathrm{min}, \mathrm{F} 0 \mathrm{~m} 2007=$ 126-109 beats $/ \mathrm{min})$, than in boys $(\mathrm{Mhm} 2007=$
115-97 beats $/ \min , \mathrm{M} 0 \mathrm{~m} 2007=117-100$ beats $/$ $\min$ ).

The results obtained after relaxation in boys vary very little compared to girls. The boys who worked in the halocamera had lower values, while the girls in the halocameras had higher values than those in the open air. In both sexes, there was a reversal between the two work regimes..

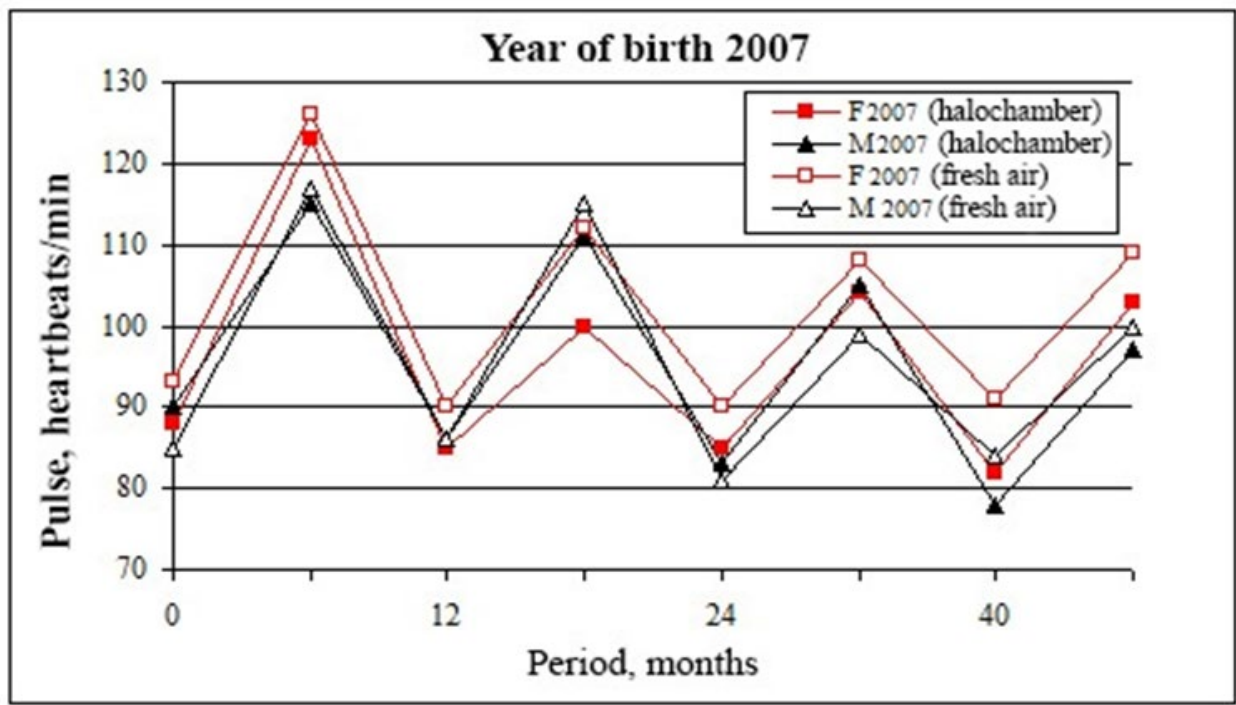

Figure 4. Evolution of the pulse for students born in 2007 studied.

\section{RESULTS AND CONCLUSIONS}

Based on the experimental data obtained on some groups of students, one witness, who worked on the sports field or in the gym and other who performed in the classrooms, differentiated on sex and by age, including children born in 2006 and 2007, the following conclusions can be drawn:

- saline aerosols and solions reformulated in situ act on the body by inhalation and absorption in 
the skin, which according to the literature offers a remedy for many diseases, halotherapy being a complementary and / or alternative method of airway protection and improvement of the morpho-structural characteristics of the human organism;

- the correct and systemic practice of movement games in an environment with solutions contributes substantially to the development of students' resistance to diseases, to a better functioning of the body and to obtaining sports performances;

- Class and physical education classes in schools in an environment with saline aerosols / solions can help the proper functioning of the body, they have a positive impact on school activities and sports competitions of students, implicitly on human performance;

- the experimental data processing system regarding the evolution of the characteristics studied, expressed by percentage increase, allowed a good highlighting of the effect of saline aerosols / solions on the biometric characteristics of morpho-structural type (weight, height, thoracic perimeter) in children, these have been studied and exposed in a previous article according to age and sex [7].

- the evolution graphs of weight and height show a higher percentage increase in the case of girls; the percentage difference between the increase registered in the group in the halochamber and that in the control group being higher in girls than in boys, although the route of the two curves for girls is sometimes below the evolution curves of growth for boys, are data that have been studied and previously presented [7].

-before performing the spirometry, a procedure performed in the school medical office, the data of human subjects (height, weight, age) were recorded, their evolution either in the halocamera, experimental group or in the room without saline aerosol generator, control group, being presented previous.

-the studies were performed for groups of students, control and experimental, on the evolution of growth in height, weight, expressed in a previous article, [7], these measurements being performed before performing spirometry, through the maximum volume of air inhaled, exhaled, then interpretation respiratory system indices, gave us a starting point and a subsequent positive evolution of respiratory parameters, both for the experimental group and for the control group, highlighting a more pronounced increase for the experimental group.

-the existing microclimate in saline, has a major contribution on the human body, numerous studies conducted so far, have registered favorable results only in the prevention and treatment of non-chronic respiratory diseases, without paying attention to the impact on intellectual and physical performance of students , grouped by age, sex, control and experimental group. The research of our team targeted high school students, on whom saline aerosols had a special influence.

- saline aerosols and solions reformulated in situ act on the body by inhalation and absorption in the skin, which according to the literature offers a remedy for many diseases, halotherapy being a complementary and / or alternative method of airway protection and improvement of the morpho-structural characteristics of the human organism [8].

- the correct and systemic practice of movement games in an environment with saline aeroanions / solions contributes substantially to the development of students' resistance to diseases, to a better functioning of the body and to obtaining sports performances [9].

- classes held in schools in an environment with saline aerosols / solions can help the proper functioning of the body, they have a positive impact on school activities and sports competitions of students, implicitly on human performance [10].

- the experimental data processing system regarding the evolution of the characteristics studied, expressed by percentage increase, allowed a good highlighting of the effect of saline aerosols / solions on some functional biometric characteristics in children, depending on age and sex;

- the difference between the percentage increases registered by the batch group and the control group born in 2006 is $11.91 \%$ for boys and only $5.21 \%$ for girls, noting that in the first 12 months the percentage increases, recorded both among the girls, as well as among the boys, they are very close, so that then the group of boys, who worked in the halochamber, will register a more accentuated growth;

- for the groups of students born in 2007 there is a clear difference between the percentage increase of the volume of exhaled air in girls compared to boys, the value of this percentage reaching up to $24.48 \%$ in the case of girls, compared to only $18.30 \%$ among boys, the lots that worked outdoors not exceeding, only very little the threshold of $15.00 \%$, throughout the monitoring registering quite close values;

- regarding the evolution of the heart rate / pulse, in the case of the group born in 2006, there is a decrease in the number of beats / minute recorded 
after exertion, which is more pronounced in boys, at the beginning of the study period, the difference between the average pulse recorded before and after exertion in the boys who worked in the halochamber it was 39 beats / min, and at the end of the period it reaches 25 beats / min, a more accentuated reduction of the difference between the values recorded at rest and those after exertion being observed after the first 24 months, where the common PIK can be attributed to health problems, which have occurred for some members of the group;

- for the groups born in 2007, the pulse registered after exertion in the first 12 months, indicates close values, both for girls and boys, after which a decrease of the number of beats/minutes is observed, the decrease being more accentuated in the case of girls, than in boys;].

\section{ACKNOWLEDGMENTS}

This work was supported by a grant of the Romanian Ministery of Research and Innovation, CCCDI UEFISCDI, project number PN-III-P1-1.2 - PCCDI-2017-0239/60PCCDI 2018, within PNCDI III.

\section{REFERENCES}

[1] Sandu I, Canache M, Sandu IG, Pascu C, Sandu AV, et., al. Researches on the NaCl Saline Aerosols III. Influence of Physical Doping with other Sals on Aerosols Generations: Aerosol and Air Quality Research, 10(6): 1731-1740, (2013)

[2] Sandu I, Canache M, Chirazi M, Sandu AV, Matei PN. et al. Artificial Halochamber for Multiple Users and Reactivation Process. Patent RO128973 (B1)/2013-11-29, 2013.

[3] Sandu I, Canache M, Lupascu T, Chirazi M, Sandu AV, et al. Artificial halochamber (embodiments), process for loading and process for reactivation of used salt granules (embodiments), Patent MD4239 (B1)/2013.07.31, 2013.

[4] Sandu I, Canache M, Mihaescu T, Chirazi M, Sandu AV, et al. Influence of $\mathrm{NaCl}$ Aerosols on the Functional Characteristics of Children., Revista de Chimie (Bucharest), Romania, 66(1): 60-65, 2015.

[5] Sandu I, Canache M, Sandu AV, Chirazi M, Mihaescu T, et al. The influence of $\mathrm{NaCl}$ aerosols on weight and height development of children, Envi Moni Asse, 187(2): 15, 2015.

[6] Sandu I., Canache M., Sandu A.V., Vasilache V. Aerosolii salini în dezvoltarea copiilor. Editura Universităţii "Alexandru Ioan Cuza" Iaşi, Romania, pp.195, 2015.

[7] Antonovici M.O., Chim. Sandu I., Chim. Vasilache V., Sandu A.V., Sandu I.G., Stangu C.C., The impact of saline aerosols on students physical performance, Acta Geobalcanica, Macedonia, vol.6/issue 2, pp.65-73,2020.

[8] Kanny G., Surdu O., Boulange M. Halothérapie et spéléothérapie : se soigner dans les mines de sel. Hegel, vol.9, Nr. 1, 2019.

[9] Ştirbu C.M., Ştirbu I.C., Sandu I., Impact Assessment of Saline Aerosols on Exercise Capacity of Athletes. Procedia - Soci and Behavi Sci , 46: 4141-4145, 2012.

[10] Pascu, C., Sandu, I., Ciobanu, G., Sandu, I.G., Vasile, V., Ciobanu, O.,Sandu, A.V., Pascu A., Method and Device for Determining Saline Aerosols "in situ".Patent RO122232/27.03.2009. 